\title{
Bio-regulatory Functions of Biliproteins and Phycobilins from Algae
}

\author{
TAKaSH HIRATA, HIROYUKI IIDA, Mikrya TANAKA, MASAKI OOIKE, TEPPEI TSUNOMURA AND MoRIHIKo \\ SAKAGUCHI \\ Graduate School of Agriculture, Kyoto University, Kyoto 606-8502, Japan (hiratan@kais.kyoto-u.ac.jp)
}

SUMMARY: Rhodophyta, Cyanobacteria or other algae contain phycobiliproteins as light-harvesting components for photosynthesis. The bio-regulatory functions of the proteins or their chromophores are introduced. It has been shown that both proteins and chromophores effectively quench various active oxygen species in vivo and in vitro. Phycoerythrobilin and phycocyanobilin, corresponding to the chromophores of phycoerythrin and phycocyanin, respectively, were mainly responsible for antioxidant activities of the chromoproteins while phycocyanin has anti-inflammatory activity partly due to its specific cyclooxigenase 2 inhibitory property of its apoprotein. Phycocyanobilin also suppressed platelet aggregation induced by both collagen and ADP.

\section{KEY WORDS: oxidation, inflammation, platelet aggregation, phycocyanin, phycoerythrin}

\section{INTRODUCTION}

Phycobiliproteins are light-harvesting components for photosynthesis in cyanobacteria, Rhodophyta, Cryptophyta and etc. Phycobiliproteins contain one or more covalently linked linear tetrapyrrole chromophores, which give intensely blue, red, blue-green or violet-blue color to the proteins. Despite the fact that algae containing these proteins have been consumed as nutritious foods in various countries, there is very limited information available on the biological functions of the proteins or the chromophores in our body.

Stocker et al. ${ }^{1)}$, reported that bilirubin in human plasma is an effective scavenger for various reactive oxygen species in vivo. The bio-regulatory functions of the proteins or the chromophores have become study subjects attracting the interest of many researchers in these years since phycocyanobilin in phycocyanin is known to have a sturucture similar to that of bilirubin.

In this paper, we summarized these functions and introduced some of them mainly on the basis of the results obtained by our investigation.

\section{SUMMARY OF FUNCTIONS}

The bio-modulating functions of biliproteins and phycobilins including antioxidative, anti-platelet aggregative, anti-neuronal damage, hepatoprotective and anti-inflammatory activities are listed in Table 1. The proteins and their chromophores show multifunctional features mainly based on their antioxidative activities. Functions of phycoerythrin have not been studied well compared with those of phycocyanin.

\section{ANTIOXIDATIVE ACTIVITY}

Fig. 1 shows typical antioxidative activities of the proteins. When the formation of linoleic acid peroxides was induced in the phosphate buffer, both R-phycoerythrin and C-phycocyanin effectively inhibited the peroxidation of linoleic acid and produced the prolonged induction periods. The rates of the peroxides formation were proportional to the decreasing rates of absorbance in visible region of each chromoprotein ${ }^{2)}$.

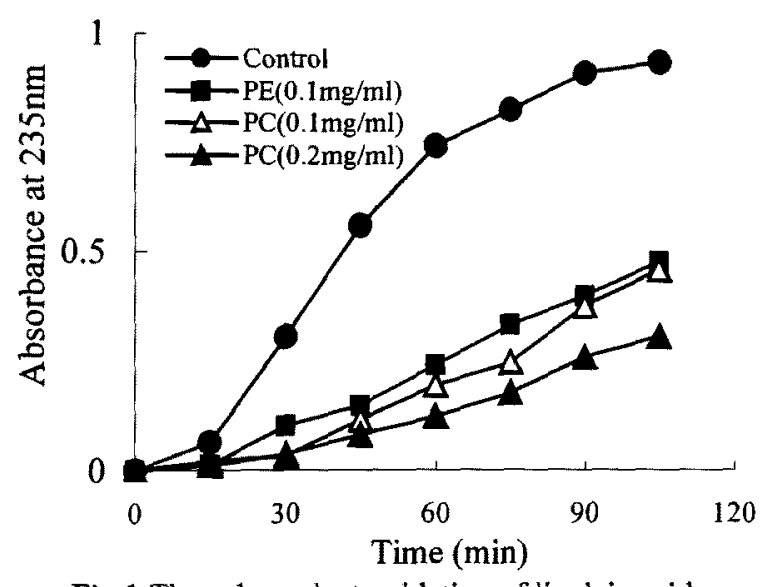

Fig.1 Time-dependent oxidation of linoleic acid with and without biliproteins. R-phycoerythrin (PE) and C-phycocyanin (PC) were extracted from laver, Porphyra sp. Linoleic acid with/without $\mathrm{PE}$ or PC in a phosphate buffer was oxidized by 2,2 'azobis (2-amidinopropane) dihydrochloride (AAPH). Linoleic acid hydroperoxides formed were periodically determined by HPLC. 
Antioxidative activities of phycocyanobilin as well as various phytochemicals were also evaluated in the phosphate buffer (Fig.2) ${ }^{3)}$. In the reaction mixture without phycocyanobilin, the oxidation of linoleic acid resulted in a linear accumulation of hydroperoxides of the acid while phycocyanobilin effectively inhibited the peroxidation of linoleic acid. Among the chemicals examined, quercetin showed the most potent antioxidative activity. These flavonoids and phenolic carboxylic acids have recently attracted the attention of many researchers. Caffeic acid has a marked radical scavenging activity among other hydroxycinnamic acids such as $p$-coumaric acid and ferulic acid. ${ }^{4)}$ A typical flavonol quercetin also act as an effective scavenger for active oxygen species, especially when they attack plasma lipoproteins and biomembranes ${ }^{5}$. Other phytochemicals except genistein also exhibit the same levels of antioxidative activities. These results indicated that phycocyanobilin has the antioxidative activity equal to those of the flavonoids and phenolic carboxylic acids ${ }^{18)}$, especially in the early stage of oxidation.

These and other experiments carried out by other groups shown in Table 1 suggested that both biliproteins and phycobilins have effective antioxidant ac-

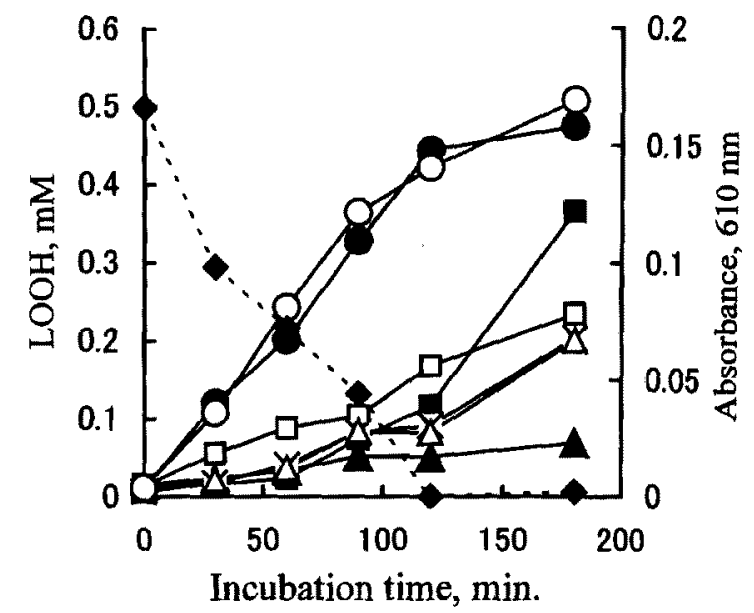

Fig.2 Antioxidative activities of phycocyanobilin (PCB) and several phytochemicals and change in absorbance of phycocyanobilin at $610 \mathrm{~nm}$. Linoleic acid with each compound was oxidized by AAPH, and hydroperoxides formed were determined by HPLC.

Each value shows the average from two measurements.

:control, $\square: P C B(10 \mu \mathrm{M}), \square$ :catechin $(10 \mu \mathrm{M})$,

$\Delta$ :quercetin $(10 \mu \mathrm{M}), \triangle$ :caffeic acid $(10 \mu \mathrm{M})$, $x$ : chlorogenic acid $(10 \mu \mathrm{M}), O$ :genistein $(10 \mu \mathrm{M})$, $\checkmark$ : absorbance of PCB at $610 \mathrm{~nm}$.

Table 1 Functions of phycobiliproteins and phycobilins

\begin{tabular}{|c|c|c|c|c|}
\hline Functions & Inducer & Target & Inhibitor & $\overline{\operatorname{Ref} .}$ \\
\hline \multirow[t]{13}{*}{ Antioxidative } & $\begin{array}{l}\mathrm{O}_{2}^{-}(\text {Xanthine oxidase }+\mathrm{Hx}) \\
\mathrm{RO} \cdot(\text { t-BOOH }) \\
\mathrm{OH} \cdot(\text { Fenton's reaction })\end{array}$ & Luminol, 2-Deoxyribose & $\overline{\mathrm{PC}}$ & 6 \\
\hline & AAPH & Linoleic acid, PC liposome & PC, PE & 2 \\
\hline & & Linoleic acid & PCB & 3 \\
\hline & & Human LDL and Chol in plasm & PCB & 7 \\
\hline & & PC liposome & PCB & 8 \\
\hline & & Direct reaction with PC & & 9 \\
\hline & AMVN & Methyl linoleate & PCB & 8 \\
\hline & $\mathrm{Cu}^{2+}$ & Human plasma & PCB & 7 \\
\hline & Leucocyte & Luminol & $\mathrm{PC}$ & 6 \\
\hline & $\mathrm{Fe}^{2+}$, Ascorbic acd & Liver microsomal lipid & PC & 6 \\
\hline & Singlet oxygen & Methyl linoleate & PCB & 7 \\
\hline & Soybean lipoxidase & Linoleic acid & PCB, PEB & 7 \\
\hline & $\mathrm{HOCl}$ & Direct reaction with PC & & 10 \\
\hline Anti-neuronal damage & Kainic acid & Hippocampus & $\mathrm{PC}$ & 11 \\
\hline Hepatoprotective & $\mathrm{CCl}_{4}$, Pulgone & Rat & $\mathrm{PC}$ & 12 \\
\hline \multirow[t]{3}{*}{ Anti-inflammatory } & $\begin{array}{l}\text { Glucose oxidase, AA, } \\
\text { TPA, Carageenan, Cotton } \\
\text { pellet }\end{array}$ & Mouse paw, ear, axilla & $\mathrm{PC}$ & $6,13,14,15$ \\
\hline & Cyclooxygenase I , II & Arachidonic acid & $\mathrm{PC}$ & 16 \\
\hline & Acetic acid & Rat colonic tissue & PC & 17 \\
\hline Anti-platelet aggregative & ADP, Collagen & Human platelet & $\mathrm{PCB}$ & This work \\
\hline
\end{tabular}


tivities in vivo as well as in vitro. However, the active sites and the antioxidative mechanisms are unknown. Some amino acid residues in a polypeptide chain are known to exhibit antioxidant activities. Wayner et $a l .,{ }^{19)}$ for example, suggested that human serum albumin highly contributes to antioxidation in the plasma, and sulfhydryl groups are responsible for the activity. Since apophycocyanins prepared from various cyanobacteria contain these antioxidant amino acid residues, ${ }^{20)}$ a possible contribution of the apoprotein to the total antioxidant activity of C-phycocyanin cannot be excluded. A remarkable antioxidative activity of phycocyanobilin obtained in Fig.2, however, suggested that the tetrapyrrol chromophore is highly responsible for the activity of biliproteins. The absorbance of phycocyanobilin $(610 \mathrm{~nm})$ rapidly decreased during the induction period, indicating the occurrence of cleavage of conjugated double bonds in the chromophore (Fig.2, dashed line). The possible cleavage of conjugated double bonds in its tetrapyrrol structure may indicate involvement of a radical addition reaction to the double bonds.

When concentrations of C-phycocyanin and phycocyanobilin in the reaction mixture were equally adjusted on the phycocyanobilin basis, and antioxidant activities of both chemicals were evaluated after adding AAPH, the activity of phycocyanobilin was almost the same as that of C-phycocyanin. ${ }^{8)}$

These results also support an idea that the antioxidant activity of C-phycocyanin is attributable to phycocyanobilin, chromophore in C-phycocyanin.

\section{ANTI-INFLAMMATORY ACTIVITY}

Recently, anti-inflammatory activity of C-phycocyanin induced by glucose oxidase was reported. ${ }^{6)}$ C-phycocyanin was orally administered to OF1 mice and one hour later glucose oxidase was injected into their hind paws. When weight differences between left and right paws were determined as edema index, C-phycocyanin effectively inhibited peroxide-induced inflammation in a dose dependent manners. Glucose oxidase generates hydrogen peroxide and subsequently hydroxyl radical. Therefore C-phycocyanin effect must be due at least in part to the scavenging of hydroxyl radical. On the other hand, this effect can be explained from the viewpoint of an inhibitory activity of C-phycocyanin against cyclooxygenase $2^{16}$. IC50 of C-phycocyanin against cyclooxygenase 2 activity was ca. $0.18 \mu \mathrm{M}$ which is very effective even when compared with that of Rofecoxib known as a specific cyclooxygenase 2 inhibitor. When C-phycocyanin was reduced, the inhibitory effect significantly decreased. This suggests that the protein structure is primarily responsible for the inhibitory activity by cyclooxygenase 2 . It is generally known that lipid peroxidation induced by free radicals activate cyclooxygenase resulting in the formation PGs from arachidonic acid. Therefore, direct inhibition of cyclooxygenase 2 by $C$-phycocyanin may lead to suppression of inflammation induced by the in vivo experiment. C-phycocyanin is also effective to suppress other types of inflammation (Table 1).

\section{ANTI-PLATELET AGGREGATIVE ACTIVITY}

Fig. 3 shows anti-platelet aggregative activity of phycocyanobilin. Fifty $\mu \mathrm{M}$ phycocyanobilin effectively control the aggregation although the effect is not drastic. Various binding sites on platelet surface activate to aggregate after calcium ion is mobilized from dense tubular system in platelet. Fibrinogen is a representative mediator to combine each platelet.

Therefore if calcium mobilization is determined, we can estimate either phycocyanobilin affects pre-mobilization or post-mobilization of calcium. About $20 \%$ mobilization was suppressed at the phycocyanobilin concentration $(50 \mu \mathrm{M})$ for $50 \%$ inhibition of platelet aggregation (Fig.4). This level of suppression for calcium mobilization does not completely explain $50 \%$ inhibition of the aggregation. However at least in part phycocyanobilin affects pre-mobilization system of calcium. C-phycocyanin may be also effective to control platelet aggregation since C-phycocyanin suppresses cyclooxygenase activity, and the mechanism of platelet aggregation

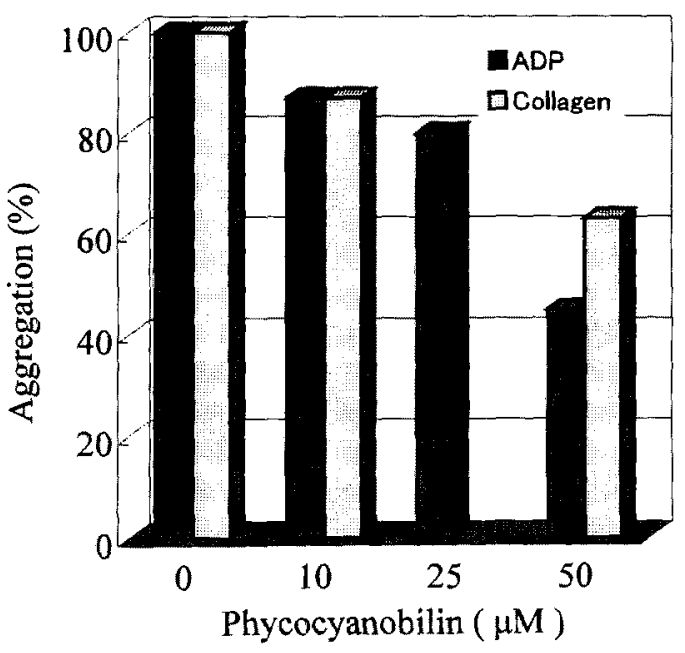

Fig.3 Platelet Aggregation Induced by ADP and Collagen. Human platelet was freshly collected and activated by ADP and collagen. Aggregation was determined with Hema Tracer 212 (MCM medical). 


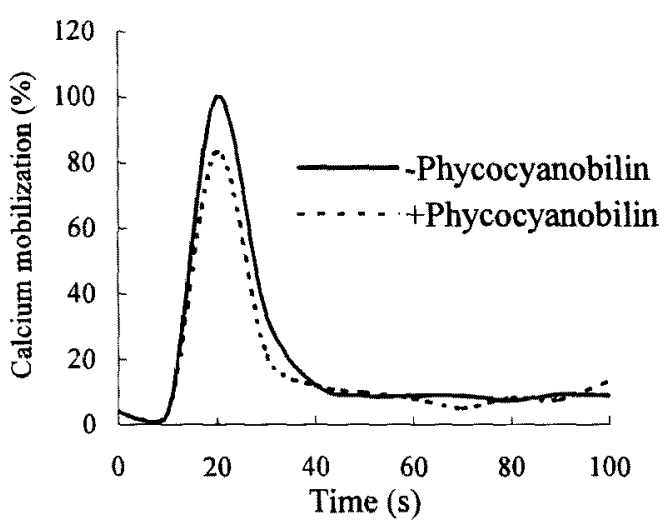

Fig.4 Relative mobilization of calcium ion from dense tubular system in platelet. Calcium in platelet was fluorometrically determined ${ }^{21)}$.

involves cyclooxygenase reactions and PGs productions from arachidonic acid.

\section{CONCLUSION}

Bio-regulatory functions, recently, has become the center of wide interest. Aquatic products including algae must be inexhaustible resources containing "functions". Further studies are required to screen and clarify functional components, and to develop food rich in "functions".

\section{REFERENCES}

1. Stocker R, Yamamoto Y, McDonagh AF, Glazer AN, Ames $\mathrm{BN}$. Bilirubin is an antioxidant of possible physiological importance. Science 1987; 235: 1043-1046.

2. Hirata T, Ooike M, Tsunomura T, Arai H, Sakaguchi M. Antioxidative activities of chromoproteins isolated from laver. Rev.Farm.Bioquim.Univ.S.Paulo. 1998; 34: 194.

3. Hirata T, Tanaka M, Ooike M, Tsunomura T, Sakaguchi M. Radical scavenging activities of phycocyanobilin prepared from a cyanobacterium, Spirulina platensis. Fisheries Sci. 1999; 65:971-972.

4. J.Terao, H.Karasawa, H.Arai, A.Nagao, T.Suzuki, and K.Takama. Peroxyl radical scavenging activity of caffeic acid and its related phenolic compounds in solution. Biosci. Biotech. Biochem. 1993; 57: 104-1205.

5. Terao J, Piskula M. Flavonoids. In: Rice-Evans CA, Packer $\mathrm{L}$ (eds). Health and Desease. Mercel Dekker, New York, 1997; 227-293.

6. Romay C, Armesto J, Remirez D, Gonzalez R, Ledon N, Garcia I. Antioxidant and anti-inflammatory properties of C-phycocyanin from blue-green algae. Inflamm Res. 1998; 47: 36-41.

7. Tanaka M. Bio-modulating functions of tetrapyrroles from aquatic lives. M.A. Thesis, Kyoto University, Kyoto, 2001.
8. Hirata $T$, Tanaka M, Ooike M, Tsunomura T, Sakaguchi M Antioxidant activities of phycocyanobilin prepared from Spirulina platensis. J.Appl.Phycol. 2000;12:435-439.

9. Lissi EA, Pizarro M, Aspee A, Romay C. Kinetics of phycocyanine bilin groups destruction by peroxyl radicals. Free Radic Biol Med. 2000;28:1051-1055.

10. Romay C, Gonzalez R, Pizarro M, Lissi E. Kinetics of c-phycocyanin reaction with hypochlorite. $J$ Protein $C h e m$ 2000; 19: 151-155.

11. Rimbau V, Camins A, Romay C, Gonzalez R, Pallas M. Protective effects of $\mathrm{C}$-phycocyanin against kainic acid-induced neuronal damage in rat hippocampus. Neurosci Lett. 1999; 276: 75-78.

12. Vadiraja BB, Gaikwad NW, Madyastha KM. Hepatoprotective effect of C-phycocyanin:Protection for carbon tetrachloride and R-(+)-Pulegone-mediated hepatotoxicty in rats. Biochem.Biophys.Res.Commun. 1998; 249:428-431.

13. Romay C, Ledon N, Gonzalez R. Further studies on anti-inflammatory activity of phycocyanin in some animal models of inflammation. Inflamm Res. 1998; 47:334-8.

14. Romay C, Ledon N, Gonzalez R. Effects of phycocyanin extract on prostaglandin $\mathrm{E} 2$ levels in mouse ear inflammation test. Arzneimittelforschung. 2000; 50:1106-1109.

15. Romay $C$, Ledon N, Gonzalez R. Phycocyanin extract reduces leukotriene $B 4$ levels in arachidonic acid-induced mouse-ear inflammation test. I Pharm Pharmacol. 1999; 51: 641-642.

16. Reddy CM, Bhat VB, Kiranmai G Reddy MN, Reddanna $P$, Madyastha KM. Selective inhibition of cyclooxygenase-2 by C-phycocyanin, a biliprotein from Spirulina platensis. Biochem.Biophys.Res.Commun. 2000; 277: 599-603.

17. Gonzalez R, Rodriguez S, Romay C, Ancheta O, Gonzalez A, Armesto J, Remirez D, Merino N. Anti-inflammatory activity of phycocyanin extract in acetic acid-induced colitis in rats. Pharmacol Res. 1999;39:55-59.

18. J.A.Vinson, Y.A.Dabbagh, M.M.Serry, and J.Jang. Plant flavonoids, especially tea flavonols, are powerful antioxidants using an in vitro oxidation model for heart disease. J. Agric. Food Chem. 1995; 43: 2800-2802.

19. Wayner DDM, Burton GW, Ingold KU, Barclay LRC, Locke SJ. The relative contributions of vitamin $E$, urate, ascorbate and proteins to the total peroxyl radical-trapping antioxidant activity of human blood plasma. Biochim. Biophys. Acta, 1987; 924: 408-419.

20. K.E.Apt, J.L.Collier, and A.R.Grossman. Evolution of the phycobiliproteins. J.Mol.Biol., 1995; 248: 79-96.

21. Qi R, Liao F, Inoue K, Yatomi Y, Sato K, Ozaki Y. Inhibition by diallyl trisulfide, a garlic component, of intracellular $\mathrm{Ca}^{2+}$ mobilization without affecting inoshitol-1,4,5-triphosphate $\left(\mathrm{IP}_{3}\right)$ formation in activated platelets. Biochem. Pharmacol. 2000; 60:1475-1483. 